\title{
LIQUID CRYSTAL POLYMER BASED OPTIMIZED NOTCH BAND MONOPOLE ANTENNA
}

\author{
B. T. P. Madhav*, T. V. Rama Krishna, B. Sindhu, B. Nikhita, G. Harshitha, \\ B. H. Prudhviraju and A. N. Meena Kumari \\ Department of ECE, K L University, Vaddeswaram, AP, India \\ *E-mail: btpmadhav@kluniversity.in
}

\begin{abstract}
An Ultra Wideband (UWB) antenna with single and dual notch bands is presented in this work by taking liquid crystal polymer as the substrate material. The proposed antenna comprises two L-shaped open ended slots with a defected ground structure. By changing the radii of circular discs and length of slots in the ground plane, single band and dual band notch characteristics are achieved. It operates from $2.9 \mathrm{GHz}-9.8 \mathrm{GHz}$ frequencies and has a size of 22 $\mathrm{X} 26 \mathrm{~mm}^{2}$. This antenna gives Omni-directional radiation pattern with a gain of $3.85 \mathrm{~dB}$. It can be operated at different frequency bands i.e.; 3.3-3.8-GHz WI-MAX, 5.15-5.85 GHz WLAN frequencies and C-band frequencies for satellite communication.

Keywords: Bandwidth, Defected Ground, Monopole, Liquid Crystal Polymer, WLAN.
\end{abstract}

(C) RASĀYAN. All rights reserved

\section{INTRODUCTION}

Ultra wide band innovation has experienced numerous developments in recent years. Printed monopole antennas received expanding consideration in UWB application because they display extremely appealing benefits, for example, wide impedance data transmission, basic structure, and Omni-directional radiation design. ${ }^{1}$ However, there still stay many difficulties in making this innovation up to its maximum potential. $^{2}$ The extensive use of ultra-wideband (UWB) was first approved by Federal Communication Commission (FCC), which has brought a drastic change in telecommunications. UWB can be designed between 3.1 to $10.6 \mathrm{GHz}$ frequencies for a wide band antenna with a bandwidth greater than $500 \mathrm{MHz} .{ }^{3,4}$ Wireless communication requires simple, low profile, minimal effort antennas. Ultra wide band (UWB) antenna meets all the essentials, where various UWB antennas have been intended for use in wireless communication systems. ${ }^{5} \mathrm{UWB}$ is the spectrum of frequencies for short distance radio communication which can perform communication with high speeds \& velocities more than $100 \mathrm{Mbps}$. Current communication systems require a solitary antenna which covers several allotted wireless frequency bands. Additionally, the design of a multi-band antenna also covers the ultra-wide band (UWB) range without falling apart. ${ }^{6}$

Many other communication systems T narrow band frequencies, such as the IEEE 802.11 wireless local area network (WLAN) focused at $5.5 \mathrm{GHz}$, where the UWB applications may be effected by possible electromagnetic interference. To avoid this, UWB antennas have been proposed by numerous significant band-notched techniques. ${ }^{7}$ Monopole antennas having a great prospect for Ultra-wideband applications due to their appealing benefits such as low power utilization, high in susceptibility to multipath fading, quicker than Bluetooth and $\mathrm{Wi}-\mathrm{Fi}$, simple fabrication and low profile. ${ }^{8,9}$ The main parameters of the antenna include return loss, radiation pattern, gain, and VSWR. In order to fulfill the requirements such as impedance bandwidth, it is difficult for an antenna to operate in UWB band. ${ }^{10}$ There are some other services at a narrow band called Wireless Local area Network and Wi-MAX which are operating at frequencies $5-6 \mathrm{GHz}$ and 3.3-6 GHz. ${ }^{11}$ The feature of our antenna is monopole with Omni-directional radiation pattern. In this antenna single and dual band notch function is provided by cutting an L-shaped slot in the radiating patch. ${ }^{12}$ By inserting a rectangular slot in ground plane notch bands will be obtained. ${ }^{13}$ Notched frequency can easily be adjusted by modifying the length of L-shaped slots. The similar 
techniques were also proposed ${ }^{14}$ by introducing the new slots like $\mathrm{L}$ and $\mathrm{U}, \mathrm{UWB}$ antennas are designed by adopting the reconfigurable notch band. This technique has been found and demonstrated as a very effective technique in giving band-notched characteristics of UWB antenna.

\section{Liquid Crystal Polymer Material}

LCP has drawn much attention for its outstanding packaging characteristics. LCP is a low-cost material with the best packing characteristics of any polymer has generated great interest in using it as a substrate material for mm-wave applications. A comparison of these packing characteristics Vs all other polymers is shown in Fig.-1. Low water absorption should be there for microwave substrate materials for better stability and reliability. Generally, for organic materials, the range of water absorption characteristics is from $0.02 \%$ to $0.25 \%$ or more.

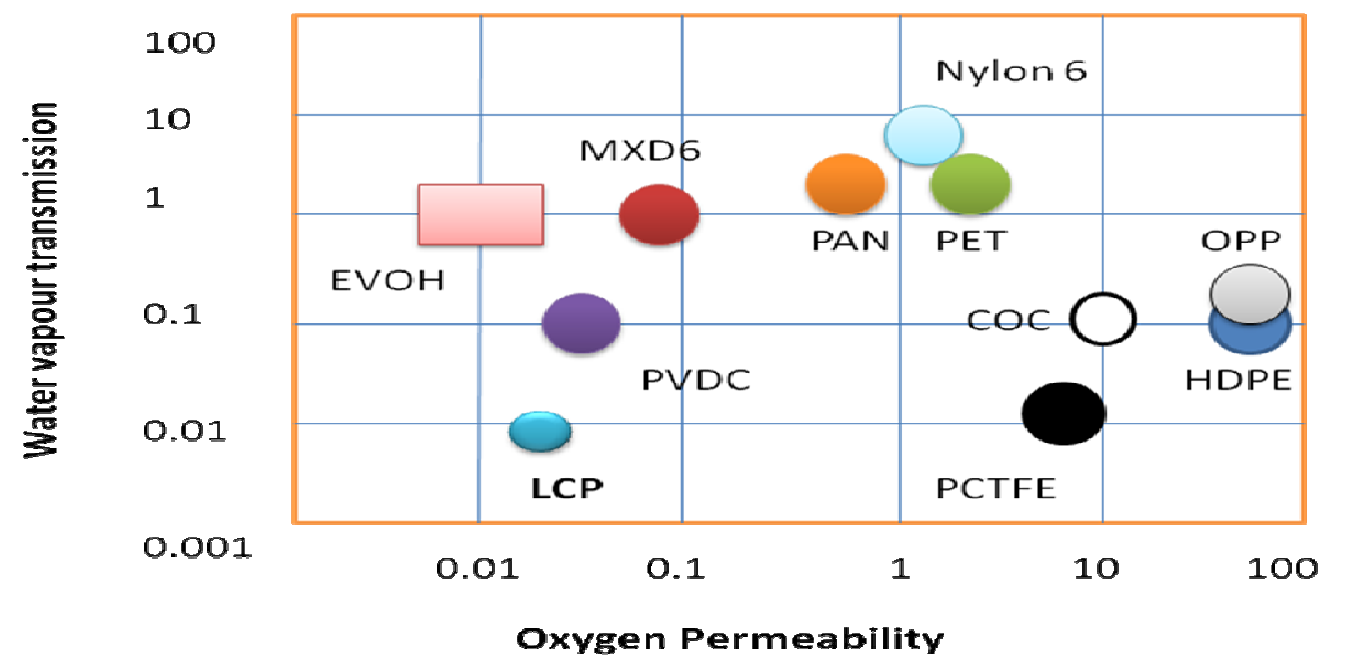

Fig.-1: Water and oxygen permeability of different polymers

\section{Antenna Design}

Figure- 2 illustrates the measurements of the proposed antenna which has outlined on the basis of microstrip antenna (MPA). It comprises of a conducting patch on one side of the dielectric substrate and a ground plane on opposite side. This antenna is fabricated on LCP substrate with relative permittivity $(\boldsymbol{E r})$ 2.9 and thickness of $0.8 \mathrm{~mm}$, length $\mathrm{L} 1=26 \mathrm{~mm}$, width $\mathrm{W} 1=22 \mathrm{~mm}$. The measurements of proposed antenna are taken by placing three circular discs of radius $\mathrm{R} 1=6.2 \mathrm{~mm}, \mathrm{R} 2=\mathrm{R} 3=5 \mathrm{~mm}$ on a conducting patch with a dielectric substrate of FR4 epoxy. The proposed antenna is microstrip feed with the resonant frequency of $5.5 \mathrm{GHz}$, Data Impedance of $50 \Omega$, Dielectric loss tangent $(\tan \delta)$ of 0.02 . The antenna parameters like Voltage standing wave ratio (VSWR), Radiation pattern, Return loss, gain at corresponding frequencies are simulated and analyzed using High-Frequency Structural Simulator (HFSS) Software.

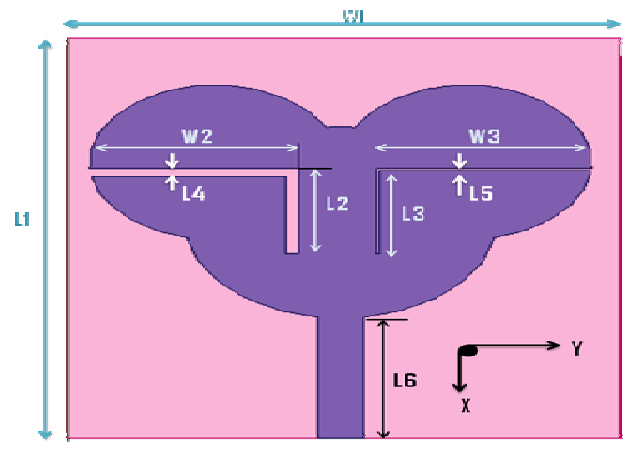

(a) Top View

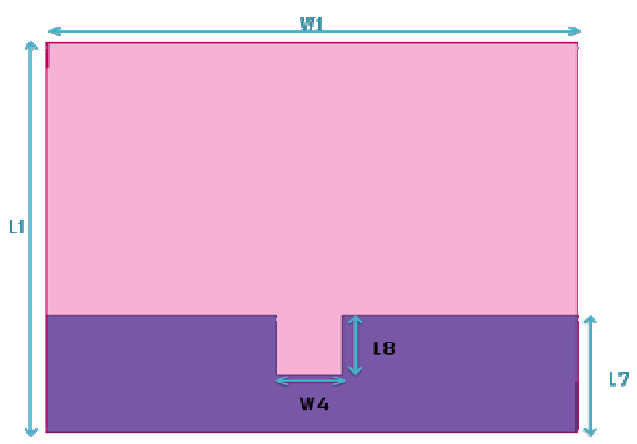

(b) Defected Ground plane

Fig.-2: The Structure of proposed Antenna model 
The above figure shows the proposed monopole antenna design which consists of the radiating patch, microstrip feed line, defected ground with a rectangular slot. The top view of substrate consists of three circular discs along with two L-shaped Slots are presented. Three circular discs are united and two Lshaped slots with the same length are considered as a patch. By changing the Length of the L-shaped slots, notch bands can be obtained easily. The schematic view of the ground plane with defected ground structure which consists of a rectangular slot. However, the ground plane configuration has much impact on the antenna characteristics and the bandwidth can be enhanced easily. The rectangular slot present in the ground plane is etched which improve the impedance bandwidth. The measurements of the slots on the patch are tabulated in Table-1.

Table-1: Antenna Dimensions

\begin{tabular}{l|l|l|l|l|l|l|l|l|l|l}
\hline Dimensions & $\mathrm{L}_{2}$ & $\mathrm{~W}_{2}$ & $\mathrm{~L}_{3}$ & $\mathrm{~W}_{3}$ & $\mathrm{~L}_{4}$ & $\mathrm{~W}_{4}$ & $\mathrm{~L}_{5}$ & $\mathrm{~L}_{6}$ & $\mathrm{~L}_{7}$ & $\mathrm{~L}_{8}$ \\
\hline Specifications (mm) & 5.5 & 8.4 & 5.5 & 8.6 & 0.5 & 1.8 & 0.1 & 7.9 & 7.8 & 4 \\
\hline
\end{tabular}

\section{Effects of notches due to various slots}

There are six models along with the proposed antenna where the first three models give single notch and the last three models give double notches in the return loss. By varying the ground slot, L slots and radius of circles single notch with an operating band of 5.04 and double notch with a bandwidth of 5.17 were obtained.

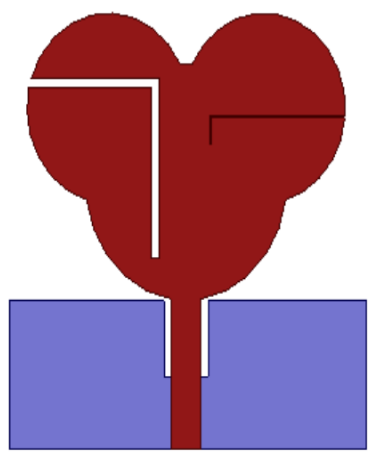

Model 1

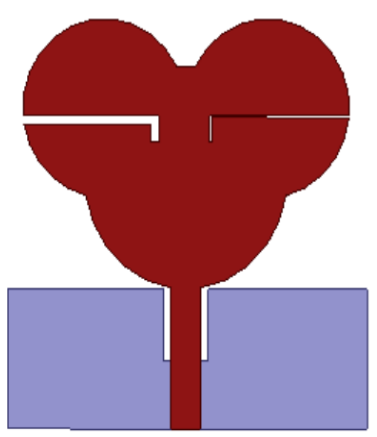

Model 4

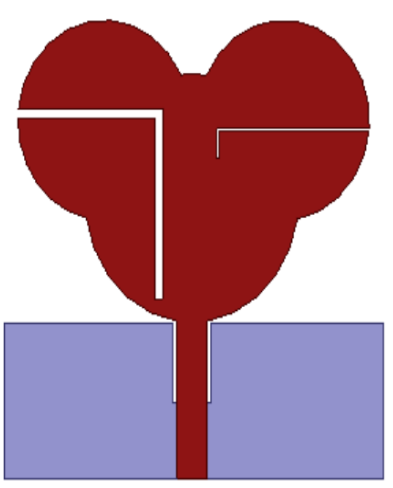

Model 2

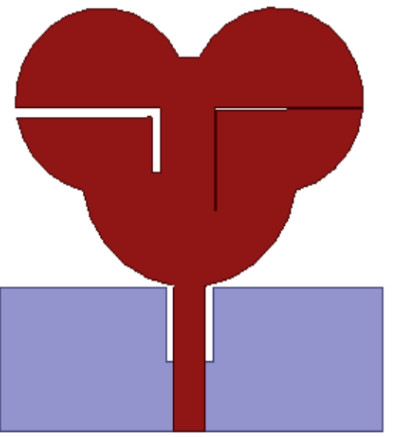

Model 5

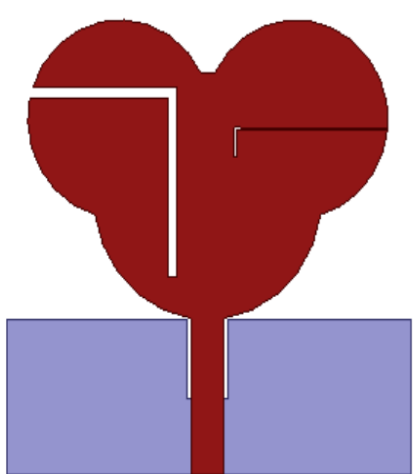

Model 3

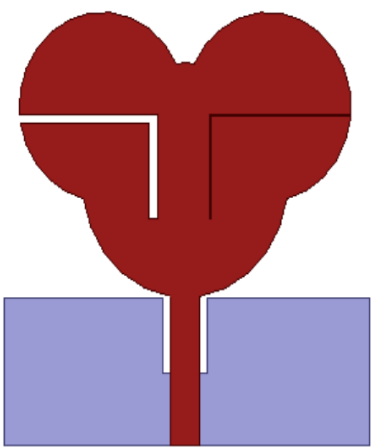

Model 6

Fig.-3: Proposed Antenna Iterations

\section{RESULTS AND DISCUSSION}

The proposed design of antenna has been simulated using Ansys HFSS. The antenna parameters like radiation patterns in E-plane $\left(\varnothing-90^{\circ}\right)$ and H-Plane $\left(\varnothing-0^{\circ}\right)$, Return Loss, VSWR, Gain have been computed 
RASĀYAN J. Chem.

Vol. 10 | No. 3 |799 - 806 | July - September | 2017

utilizing HFSS and results for all six models can be compared \& validated. Different comparisons of different simulated models are tabulated as follows:

Table-2: Antenna Models with operating Frequency and Gain

\begin{tabular}{c|c|r|c}
\hline S. No. & Model & Operating Frequency $(\mathrm{GHz})$ & Gain $(\mathrm{dB})$ \\
\hline 1 & Model 1 & $3.8018-4.5909$ & 3.6185 \\
& & $5.0254-9.7484$ & 3.7506 \\
\hline 2 & Model 2 & $3.7412-4.5882$ & 3.8723 \\
& & $3.7059-9.7412$ & 2.1320 \\
\hline 3 & Model 3 & $4.8539-9.8451$ & \\
\hline 4 & Model 4 & $3.3901-3.9099$ & 1.9542 \\
& & $5.2249-4.9339$ & \\
\hline 5 & Model 5 & $2.9975-9.4625$ & 3.8528 \\
& & $3.6531-4.1449$ & \\
\hline 6 & Model 6 & $5.2427-9.7370$ & \\
& & $2.9412-3.0824$ & \\
& & $3.5294-3.6688$ & \\
\hline
\end{tabular}

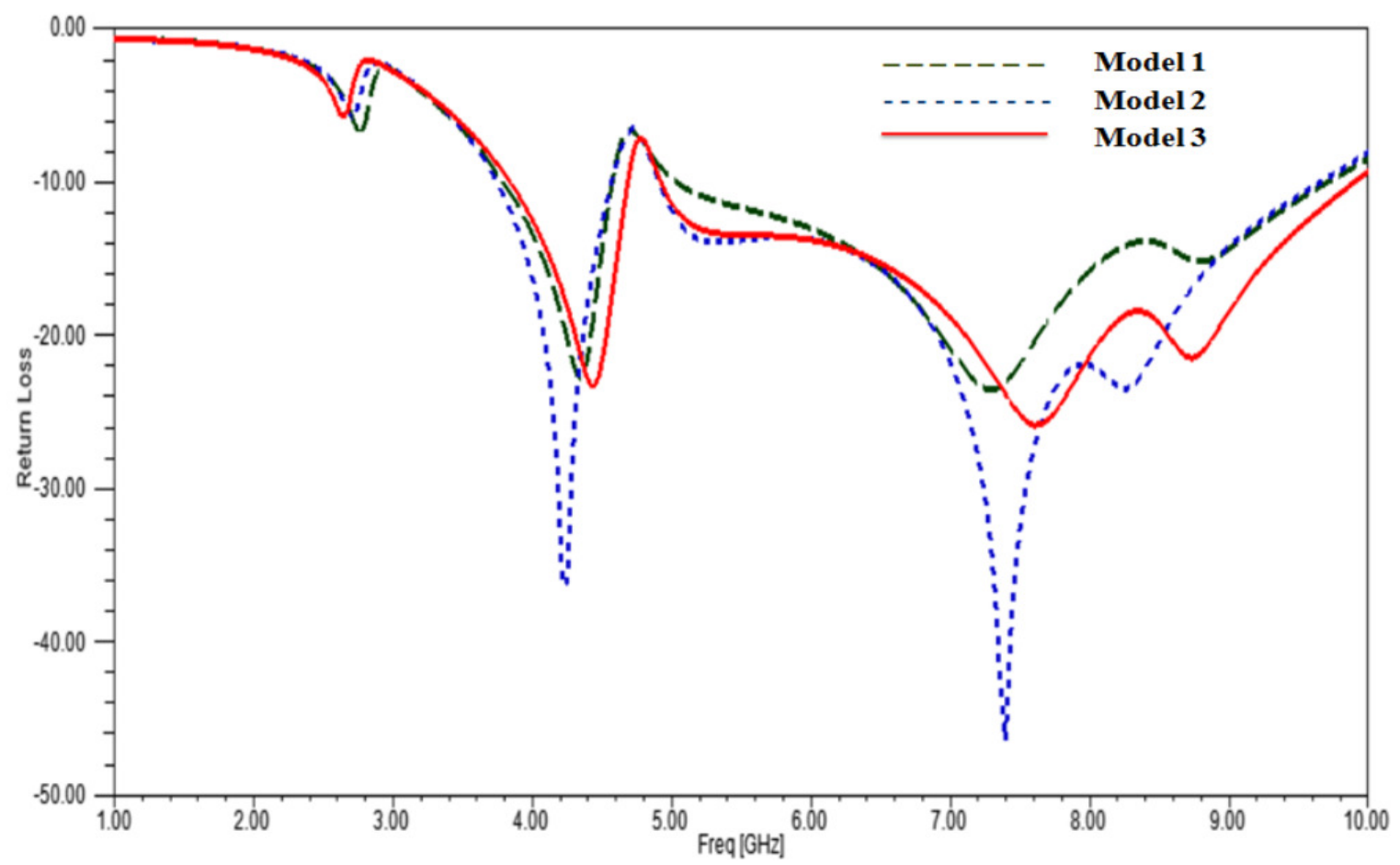

Fig.-4: Return Loss for Single Notch

Return loss is can be defined as the loss of power or the signal returned/reflected by a discontinuity which is present in a transmission line or optical fiber. This discontinuity can be a mismatch due to the terminating load or a device inserted in the line. It is usually expressed as a ratio in decibels (dB). Bands obtained for proposed antenna are $2.94 \mathrm{GHz}-3.08 \mathrm{GHz}$ centre frequency $3.02 \mathrm{GHz}$ and return loss $15.6 \mathrm{~dB}, 3.52 \mathrm{GHz}-3.66 \mathrm{GHz}$ centre frequency $3.61 \mathrm{GHz}$ and return loss $13.0 \mathrm{~dB}, 4.62 \mathrm{GHz}-9.80 \mathrm{GHz}$ centre frequency $7.55 \mathrm{GHz}$ and return loss $23.5 \mathrm{~dB}$ is achieved. From above graph, it is evident that model 3 exhibits a minimum return loss of $-47 \mathrm{~dB}$ with two operating bands. 
The simulation of the proposed antenna gives triple frequencies for dual notches at $3.0 \mathrm{GHz}, 3.6 \mathrm{GHz}$ and 7.5 GHz. By comparing the return loss of the three models 4,5 and 6 two notch bands are obtained. However, return loss for model 4 and 5 is more significant compared to model 6.Two narrow bandwidths are obtained for model 6 within the range 2.9412-3.0824 and 3.5294-3.6688.

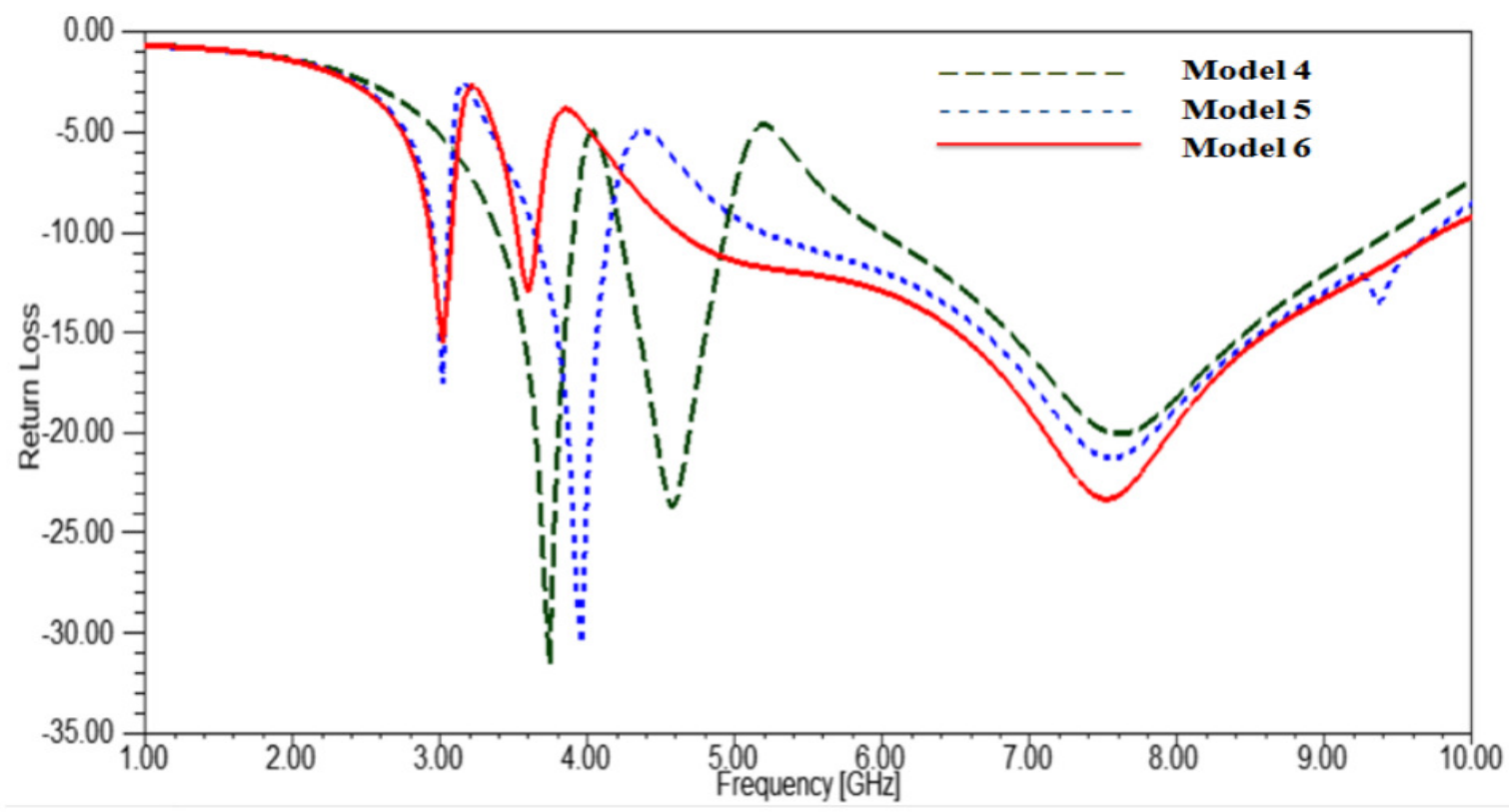

Fig.-5: Return Loss for Double Notch

The VSWR (Voltage Standing Wave Ratio) is always a real and positive number for antennas. The smaller the VSWR is, the better the matching of the antenna to the transmission line which results in more power delivered to the antenna. The minimum VSWR is 1.0. In this case, no power is reflected from the antenna, which is ideal. The plots of VSWR Vs frequency for the different models are shown in Figure below.

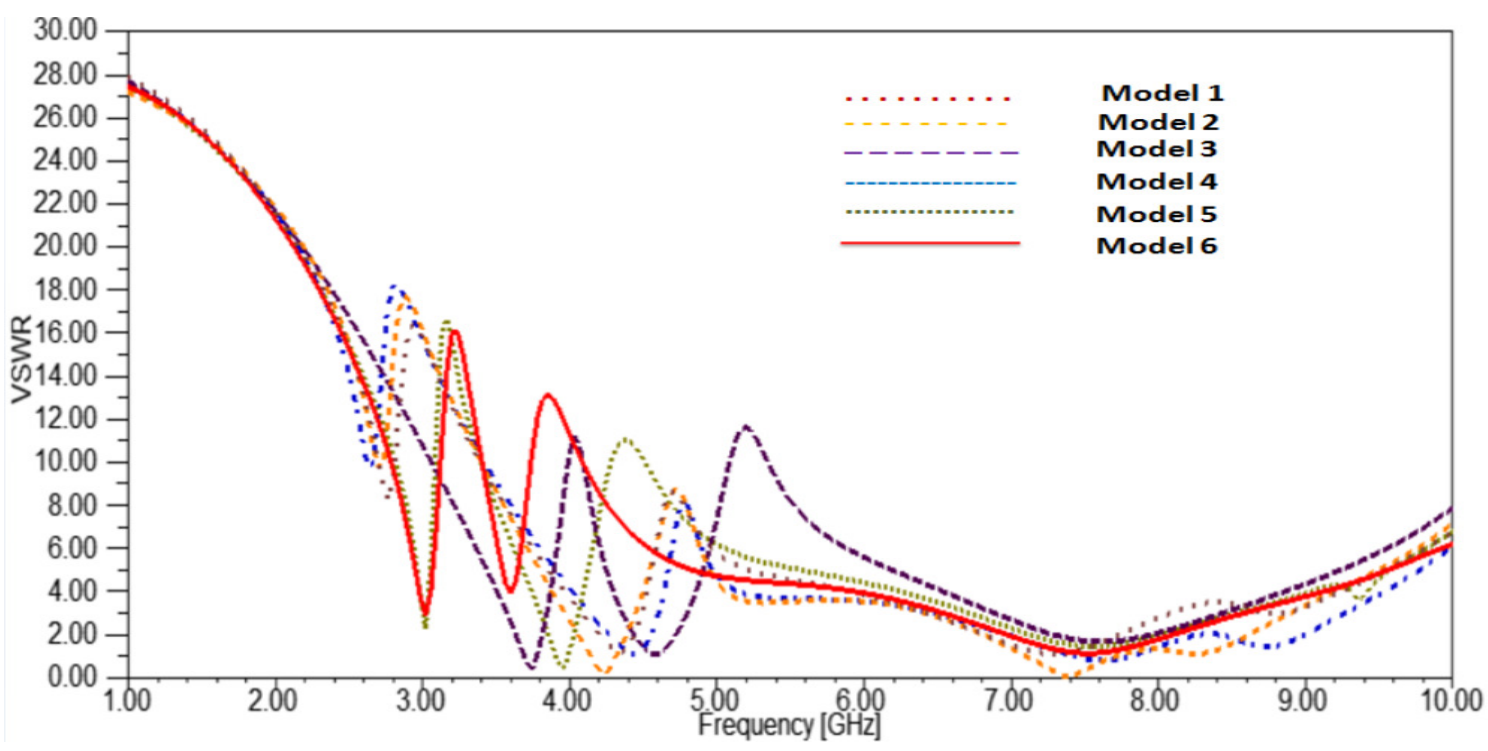

Fig.-6: VSWR for single and double notches 
The results above are the radiation patterns at maximum operating frequency for six models. The patterns shown below are those resulting from a perfect dipole formed with Omni-directional pattern. Omnidirectional antennas are commonly referred to as "Omnis." The Omni directional antenna radiates and receives equally well in all horizontal directions. The gain of an Omni-directional antenna can be increased by narrowing the beam width in the vertical or elevation plane. In the below graph 4.GHz to 9.5 GHZ positive gain can be considered, where the operating frequency is same and at a $6.8 \mathrm{GHz}$ maximum gain of 3.8 is observed.

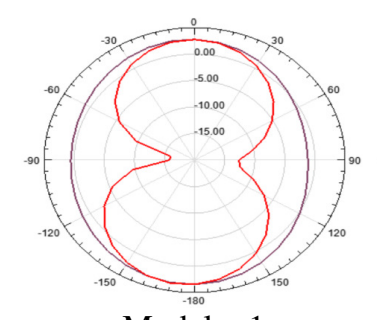

Model - 1

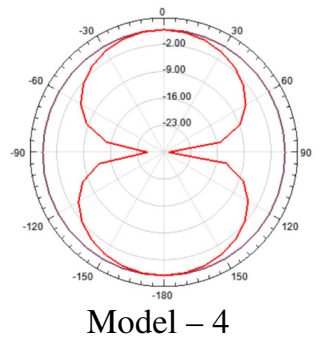

Model - 4

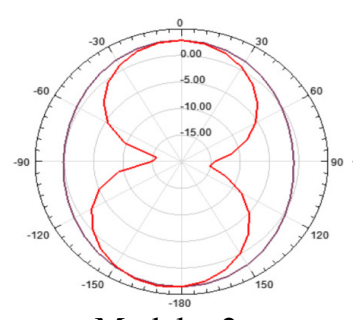

Model -2

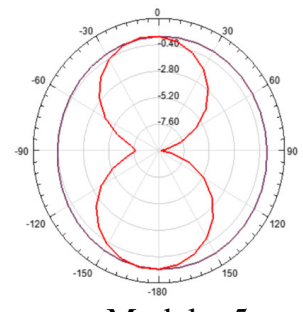

Model - 5

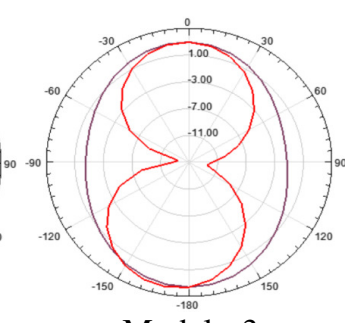

Model - 3

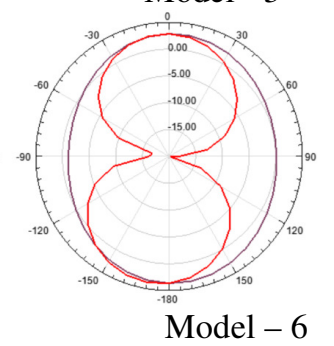

Fig.-7: Radiation Patterns for six models

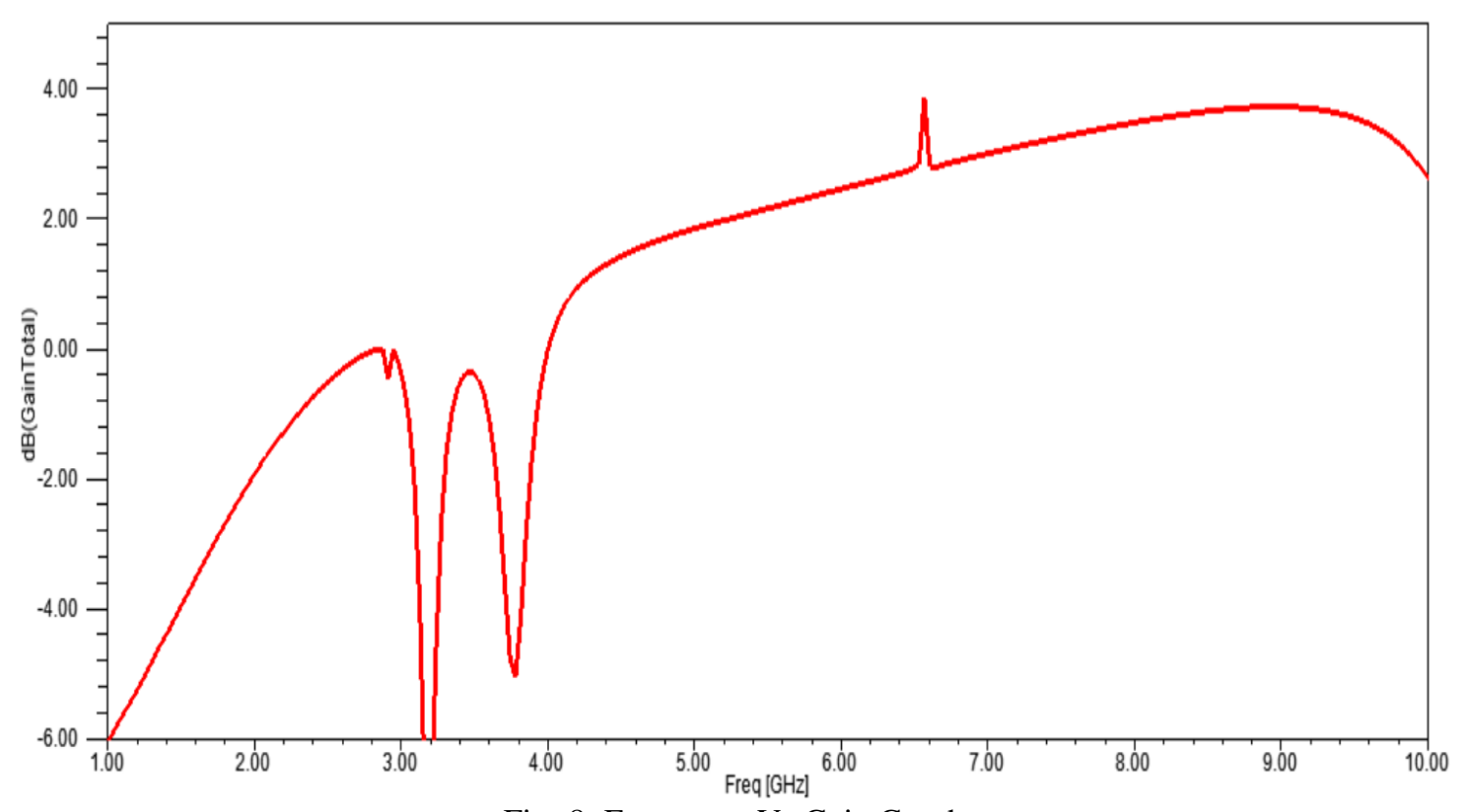

Fig.-8: Frequency Vs Gain Graph

\section{LCP Based Antenna Results}

Ultralam ® 3850 is the emerging liquid crystalline polymer circuit material from Rogers Corporation. The features like excellent high-frequency properties, good dimensional stability, external low moisture absorption and flame resistant make this as one of the potential substrate material for RF circuit design. The liquid crystal polymer based antenna is providing excellent reflection coefficient results with a shift 
in frequency from one model to another. The tenability in the frequency is due to the change in slot positions in the notch band antenna.

\section{CONCLUSION}

A novel technique for enhancing the bandwidth of an LCP based microstrip patch antenna with single and dual band characteristics along with a wide bandwidth capability for broadband applications is designed and discussed. Microstrip patch antenna for wireless applications covering 2.94 to $9.80 \mathrm{GHz}$ frequency along with notches has been presented. The proposed UWB antenna provides high bandwidth, return loss up to $-23.5 \mathrm{~dB}$. The simulated result of design antenna shows good performance and thus can be used as various wireless applications such as Wi-MAX, WLAN, C-band satellite communication and mobile communication.

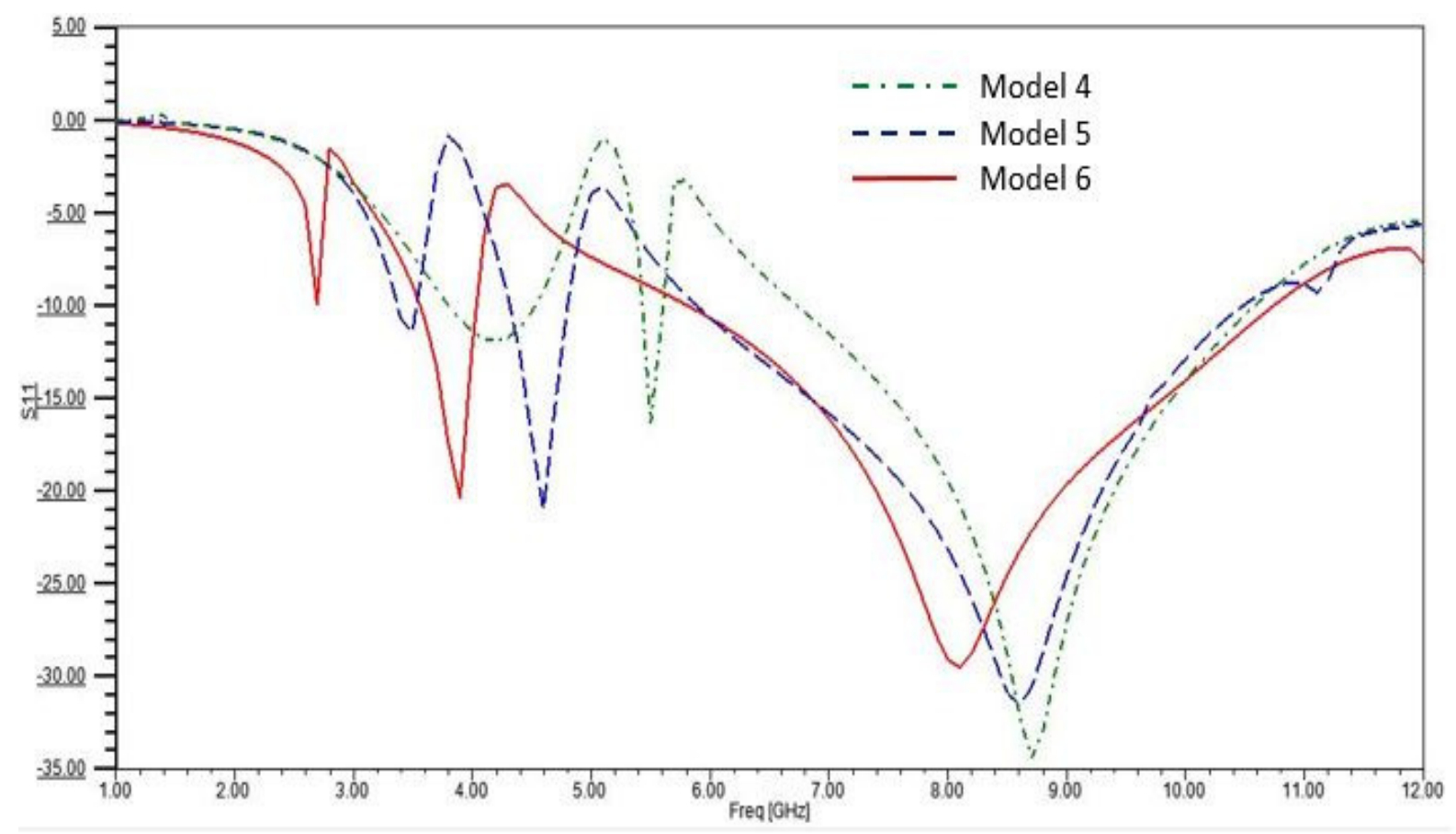

Fig.-9: Reflection Coefficient of LCP based notch band antennas

\section{ACKNOWLEDGEMENT}

The authors deeply express their gratitude to ARL-LC Research Centre, Department of ECE, K L University for their encouragement during this work. Further, Madhav would like to express his gratitude to DST through grant ECR/2016/000569 and FIST grant SR/FST/ETI-316/2012.

\section{REFERENCES}

1. B. T. P. Madhav, V.G.K.M. Pisipati, K. V. L. Bhavani, P. Sreekanth and P. Rakesh Kumar, Journal of Theoretical and Applied Information Technology, 18 (1), 62 (2010).

2. Jiabin $\mathrm{Xu}$, Dacheng Dong, Shaojian Chen, Zhouying Liao and Gui Liu, Progress In Electromagnetics Research C, 53 (8), 11 (2014).

3. B.T.P. Madhav, V.G.K.M. Pisipati, N.V.K Ramesh, Habibulla Khan and P.V.Datta Prasad, Journal of Engineering and Applied Sciences, 6 (4), 98 (2011).

4. Peng Gao, Shuang He, Xubo Wei, Ziqiang Xu, Ning Wang, and Yi Zheng, IEEE Antennas and Wireless Propagation Letters, 13 (2), 376 (2014).

5. B. T. P. Madhav and V. G. K. M. Pisipati, International Journal of Applied Engineering Research, 6 (9), 1099 (2011). 
RASĀYAN J. Chem.

Vol. 10 | No. 3 |799 - 806 | July - September | 2017

6. B. T. P. Madhav, V.G.K.M. Pisipati, Habibulla Khan, V.G.N.S Prasad, K. Praveen Kumar, K.V.L. Bhavani and M. Ravi Kumar, Journal of Engineering Science and Technology Review, 4 (2), 131 (2011).

7. Nasser Ojaroudi and Mohammad Ojaroudi, IEEE Antennas and Wireless Propagation Letters, 12 (2), 182 (2013).

8. B. T. P. Madhav and V. G. K. M. Pisipati, Solid State Phenomena, 181 (3), 289 (2012).

9. Qing-Xin Chu and Ying-Ying Yang, IEEE Transactions on Antennas and Propagation, 56 (12), 3637 (2008).

10. B. T. P. Madhav and Harish Kaza, Leonardo Electronic Journal of Practices and Technologies, 26 (14), 103 (2015).

11. B. T. P. Madhav and A. Manikanta Prasanth, ARPN Journal of Engineering and Applied Sciences, 10 (2), 747 (2015).

12. B. T. P. Madhav and Harish Kaza, Journal of Theoretical and Applied Information Technology, 76 (1), 42 (2015).

13. P. Lakshmikanth, Kh. Takeshore, B.T.P. Madhav, Journal of Engineering and Applied Sciences, 10 (3), 40 (2015).

14. M. L. S. N. S. Lakshmi, ARPN Journal of Engineering and Applied Sciences, 11 (13), 8349 (2016).

[RJC-1653/2017] 